\title{
VALORIZAÇÃO DOS RECURSOS LOCAIS: RELAÇÕES ENTRE OS OBSTÁCULOS DA CADEIA DE PRODUTOS DO EXTRATIVISMO E A GESTÃO DO DESIGN.
}

\section{THE VALORIZATION OF LOCAL RESOURCES: RELATIONS BETWEEN THE EXTRACTIVISM PRODUCT CHAIN AND DESIGN MANAGEMENT.}

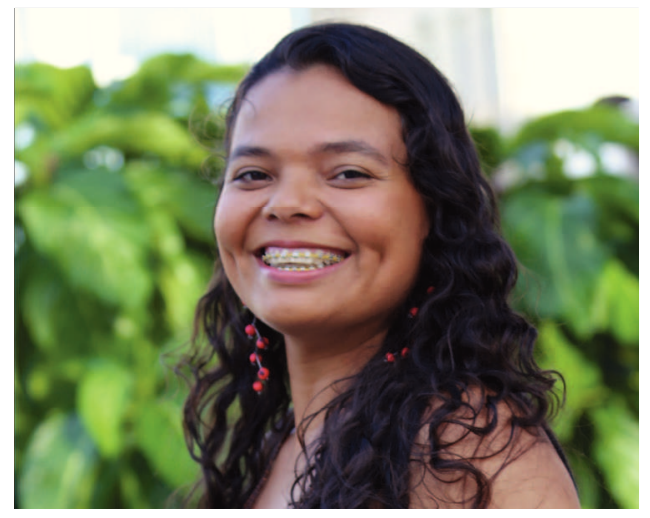

\section{Valkiria Aires Viegas}

Mestre em Design, Universidade Federal do Maranhão Diretoria de Desenvolvimento de Ensino, Instituto Federal de Educação, Ciência e Tecnologia do Maranhão valviegas@hotmail.com

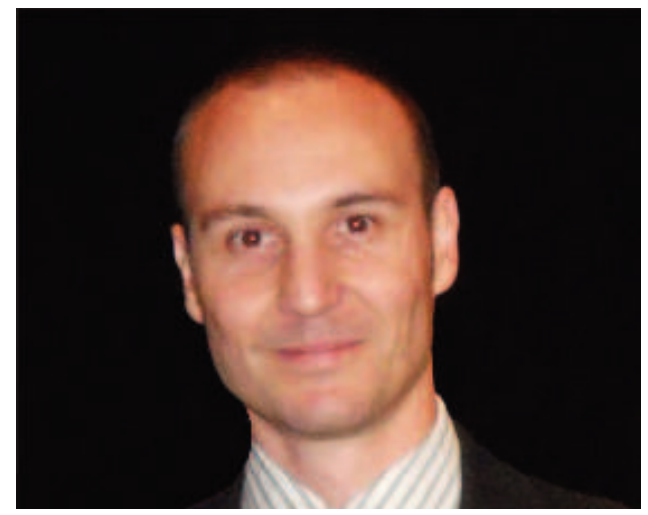

\section{André de Souza Lucca}

Doutor em Ciências do Design, Università luav di Venezia Itália

Programa de Pós-graduação em Design, Universidade

Federal do Maranhão

aslucca@yahoo.com.br

\section{RESUMO}

Como uma ferramenta estratégica para a inovação centrada nos recursos e nas competências de um território, o Design pode atuar não só na identificação de produtos, serviços e valores existentes, mas também, visualizando conexões e novos cenários por meio de uma visão holística do complexo sistema econômico, social e cultural onde o extrativismo está inserido. Baseada numa revisão bibliográfica narrativa, o presente texto adota uma perspectiva multidisciplinar priorizando uma visão projetual e envolvendo conhecimentos da área de gestão do Design aplicada ao setor extrativista. Foram selecionadas quatro cadeias produtivas de produtos extrativistas: o babaçu, a castanha do Brasil, o açaí e os recursos pesqueiros, com o objetivo de relacionar os principais problemas enfrentados e identificar os níveis de atuação e da gestão do Design. 


\section{PALAVRAS-CHAVE}

Gestão do Design. Valorização local. Extrativismo.

\section{ABSTRACT}

Design, as a strategic tool for innovation centered around the resources and competencies of a territory, can not only look to identify products, services and current values, but also visualize connections and new scenarios through holistic envisioning of the complex economic, social and cultural system where extractivism is inserted. Based on a bibliographic review narrative, this text adopts a multidisciplinary perspective prioritizing a projectual vision and involving knowledge of Applied Design management to the extractivist sector: Babaçu, Brazil nut, açaí and fishing resources in order related the main problems faced by the sector identifying performance and Design management levels.

\section{KEYWORDS}

Design Management. Local valorization. Extractivism.

\section{INTRODUÇÃO}

O Brasil possui uma grande biodiversidade, em especial, na região amazônica, utilizada por muitas populações como meio de subsistência. Nessa região, as lutas em defesa do uso da terra e da preservação do meio ambiente, que por vezes se confundem, fortalecem a união das comunidades presentes no território. Um exemplo disso são as atividades extrativistas, que sempre estiveram presentes ao longo da história do país, e que em vários momentos estiveram unidas com os movimentos ambientais e socais, como nas lutas dos seringueiros no Acre e das quebradeiras de coco babaçu no Maranhão.

Contudo, antes de se discutir o propósito deste texto, é necessário definir o extrativismo. Para Rueda e Murrieta (1995), geralmente, o termo é designado para toda atividade de coleta de produtos de origem mineral, animal e vegetal, menciona também que o termo "extração" está associado a recursos naturais, que não tenham sidos intencionalmente ampliados para serem explorados. E mais, percebe esta atividade como a utilização sustentável dos recursos, tendo em vista a experiência de reservas extrativistas.

No entanto, Correa (2005 apud HOMMA, 2008) adverte que diversas megarreservas extrativistas apresentam sustentabilidade duvidosa, por se apoiarem na extração madeireira e em atividades agrícolas. Geralmente, considera-se que a extração vegetal de recurso não madeireiro, como a coleta de castanhas, açaí, buriti, babaçu, etc. ou de recursos renováveis como os pesqueiros, sejam sustentáveis. Nesse sentido, Homma (2008) afirma ser uma falsa concepção, pois a extração econômica muitas vezes não garante o equilíbrio biológico e viceversa, e mais, se deve levar em conta a resiliência da área de extração, assim como, as características específicas de cada produto e seus processos de beneficiamento e comercialização.

Segundo Krucken (2009), estimular o reconhecimento das qualidades e valores relacionados a um produto local, significa contar a história por trás do produto, e isso, por sua vez, significa comunicar elementos culturais e sociais. Esse reconhecimento contribui para a proteção do patrimônio material e imaterial e da diversidade cultural, e também, para a valorização de práticas sustentáveis em todo ciclo de vida dos produtos.

É nesse ponto que o Design pode atuar, fornecendo ferramentas estratégicas para a busca da inovação centrada nos recursos e nas competências de um território, como aponta Krucken (2009). Buscando não só identificar os produtos, os serviços e os valores existentes, mas também, visualizando conexões e novos cenários através de uma visão holística do complexo sistema econômico, social e cultural que o extrativismo está inserido.

Devido a natureza do objeto de estudo e por se tratar de uma revisão 
bibliográfica narrativa, adotou-se uma perspectiva multidisciplinar na condução deste trabalho, priorizando a perspectiva projetual e envolvendo conhecimento de áreas relacionadas com a gestão do Design. Foram selecionadas quatro cadeias produtivas de produtos oriundos do extrativismo: o babaçu, a castanha do Brasil, o açaí e os recursos pesqueiros, no intuito de relacionar os principais problemas enfrentados por setor com os níveis de atuação da gestão do Design.

A importância deste estudo se dá no relacionamento entre os principais problemas das cadeias produtivas do extrativismo e os níveis de atuação da gestão do Design, sendo útil para designers, empreendedores locais e gestores públicos que interagem direta ou indiretamente com projetos, programas ou campanhas para fomentar, valorizar e promover os patrimônios locais.

\section{MÉTODO}

Este artigo apresenta os resultados obtidos a partir de uma revisão bibliográfica narrativa, caracterizada como uma etapa de pesquisa exploratória, de abordagem qualitativa, cujo objetivo primário foi compreender o panorama atual do sistema produtivo do babaçu no estado do Maranhão .

A etapa de revisão bibliográfica narrativa auxiliou no mapeamento da cadeia produtiva do babaçu no Maranhão, na identificação e classificação dos modelos organizacionais relacionados com a cadeia do babaçu no Maranhão, na identificação das estratégias de design orientadas para a valorização dos recursos locais e na seleção das quatro cadeias produtivas estudadas que permitiram a construção das relações entre os principais problemas enfrentados por setor com os níveis de atuação da gestão do Design.

A revisão bibliográfica narrativa é um estudo do tipo "estado da arte" similar ao utilizado no campo educacional. Na área da saúde, estes estudos são denominados "revisão narrativa" e têm por característica permitir estabelecer relações com produções bibliográficas anteriores, identificando temáticas recorrentes, apontando novas perspectivas, consolidando uma área de conhecimento e constituindo-se orientações de práticas pedagógicas para a definição dos parâmetros de formação de profissionais para atuarem na área (ROCHA apud VOSGERAU e ROMANOWSKI, 2014).

Segundo Noronha e Ferreira (apud VOSGERAU e ROMANOWSKI, 2014):

Nesse tipo de estudo, são analisadas as produções bibliográficas em determinada área [...] fornecendo o estado da arte sobre um tópico específico, evidenciandonovas ideias, métodos, subtemas que têm recebido maior ou menor ênfase na literatura selecionada (NORONHA e FERREIRA apud VOSGERAU e ROMANOWSKI, 2014).

Este tipo de revisão apresenta uma temática mais aberta. Dificilmente parte de uma questão específica bem definida, não exigindo um protocolo rígido para sua confecção. A busca das fontes não é pré-determinada e específica, sendo frequentemente menos abrangente. A seleção dos artigos é arbitrária, provendo o autor de informações sujeitas a viés de seleção, com grande interferência da percepção subjetiva.

\section{RESULTADOS}

\subsection{O DESIGN COM ATUAÇÃO NO TERRITÓRIO}

De acordo com Krucken (2009), o Design aplicado em escala regional se constitui em uma ferramenta importante para uma reconfiguração e/ou potencialização das capacidades de oferta de empresas locais para atingir mercados globais. E, ao focar sua ação sobre um território e não mais sob uma empresa ou produto, muitas oportunidades podem surgir, como por exemplo:

- $\quad$ Na identificação e exploração sustentável do potencial dos recursos e das competências situadas no território; 
- No Projeto e desenvolvimento de produtos e serviços diferenciados e com alto valor agregado localmente, com base nos recursos, nas competências disponíveis e na riqueza cultural;

- Nos Processos colaborativos de inovação e aperfeiçoamento do design local. Pelos quais se promova o diálogo de tradição e inovação e se fortaleça o sentido de pertença da comunidade;

- No Desenvolvimento de uma cultura de coprodução de valores e processos produtivos colaborativos;

- No Fortalecimento da imagem do território e de seus produtos e empresas;

- $\quad$ No Projeto de novas interfaces e formas de intermediação entre os produtores e entre produtores e consumidores (redes e cadeias de valor), envolvendo os recursos e potencialidades das empresas e do território;

- $\quad$ No Resgate de valores e da cultura local e desenvolvimento de produtos a partir de matérias-primas alternativas disponíveis no território, além de utilização de subprodutos e resíduos.

Vinculado à sustentabilidade, o Design adota uma visão holística, ainda que voltada para a localidade. Mozota (2011) ressalta que essa abordagem considera os seguintes pontos:

- Completa avaliação das condições do local;

- $\quad$ Aplicação da eficiência energética e estratégica de conservação;

- Uso adequado de materiais;

- $\quad$ Redução, reutilização e reciclagem e todos os níveis;

- Vinculação do projeto com a comunidade enquanto se cria um maior senso de comunidade.

Essas percepções podem auxiliar na mudança de ações junto as comunidades extrativistas, onde por muitas vezes as ações estão focadas, tão somente, na implementação de unidades de beneficiamento. No entanto, conforme Diniz (2008), para que estratégias vinculadas com essa abordagem sejam eficazes na valorização produtos do extrativismo, como no caso do babaçu, da castanha do Brasil, do açaí, dos recursos pesqueiros, entre outros, não basta ter vontade política de implementar unidades de beneficiamento nas comunidades. Essas unidades devem ser apoiadas num sistema de gestão adequada à realidade local e ter apoio de diversos setores.

Assim, se é necessário um sistema de gestão, cabe verificar quais elementos da gestão do Design que podem contribuir para projetos de valorização dos recursos locais.

\subsection{A GESTÃO DO DESIGN}

A gestão do Design não está vinculada somente ao processo de dar forma visível a um determinado negócio ou estratégia de marketing, mas, concentrase na promoção de mudanças de comportamento e da visão corporativa. De modo que as características do designer - como criatividade, iniciativa, atenção aos detalhes, preocupação com o cliente - se unam com as características dos dirigentes empresariais para sustentar a gestão da mudança. Além disso, possui dois objetivos: Familiarizar os gerentes/administradores com o Design e os designers com a gestão; e desenvolver métodos de interação do Design com o ambiente corporativo (MOZOTA, 2011).

Mozota (2011), ainda ressalta alguns aspectos para a implementação do Design na gestão das empresas:

- $\quad$ Para tornar-se eficaz, o Design deve ser introduzido em uma organização de maneira gradativa, responsável e deliberada;

- $\quad$ design é um processo interno que integra pesquisa de mercado, estratégia de marketing, marca, engenharia, desenvolvimento de novo produto, planejamento da produção, distribuição e políticas de comunicação corporativa; 
- Para que seja bem-sucedida, a implementação do Design só pode ocorrer se certos objetivos centrais forem perseguidos, tais como qualidade dos produtos ou diversificação da gama de produtos;

- $\quad$ Podem ser programadas diferentes ações de design. Isso implica estudar as fases do produto no seu ciclo de vida antes de esclarecer a política de design.

Na prática da gestão do Design sob o ponto de vista da tomada de decisão, pode ser classificada em três níveis: operacional, funcional ou tático e estratégico. No nível operacional, a gestão do Design foca-se principalmente no projeto de design, sendo o primeiro passo para incorporação do Design na empresa. No nível funcional ou tático, se defini em etapas mais avançadas, em que se assume uma função ou um departamento e se adquire interdependência com ou demais setores. E por fim, o nível estratégico é o mais alto estágio de integração do Design, quando este passa a estar ligado diretamente com a estratégia competitiva da organização (CASAS e MERINO, 2011; MOZOTA, 2011).

Figura 1 - Níveis da gestão do Design, de acordo com a tomada de decisão

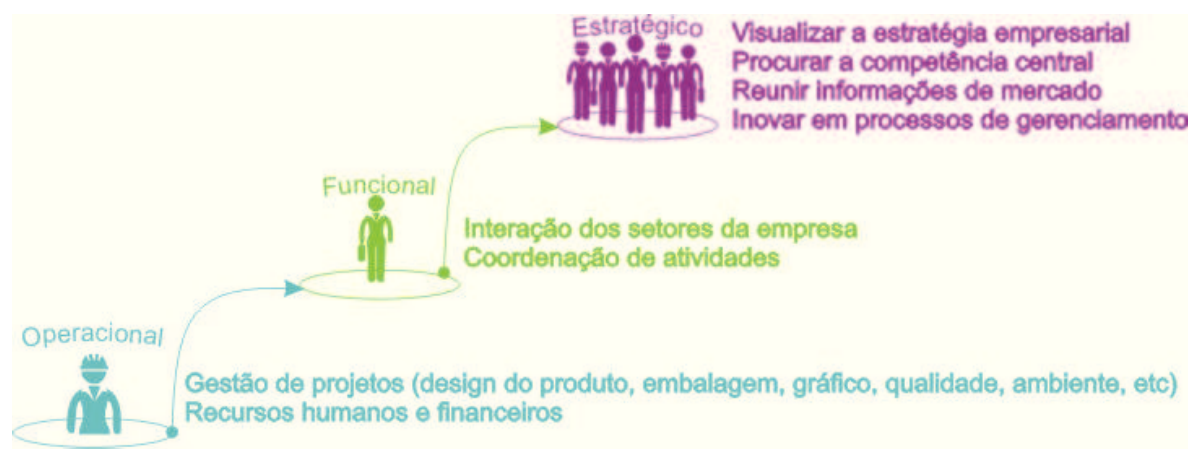

Fonte: Autora, adaptado de MOZOTA, 2011; CASAS e MERINO, 2011

A implementação do design deve acontecer de forma gradual, a melhoria evolutiva de inovações anteriores e do design existente é uma estratégia mais confiável para o sucesso do que a tentativa de introduzir novos produtos inovadores. Além do que para os colaboradores a mudança pode ser percebida como uma perda. De modo que, a empresa deve assegurar que a mudança seja percebida como necessária, e não imposta, para incentivar o treinamento enquanto garante a continuidade e para tratar o problema da resistência à mudança a fim de certificar-se de que a nova realidade seja aceita (MOZOTA, 2011).

A alocação de recursos de design, será implementada conforme a estratégia de design adotada pela empresa, devendo considerar que algumas ações estão mais propicias a apresentar resultados mais rápidos ou que são mais necessários e urgentes. Uma empresa, pode considerar que os componentes visuais são mais importantes, assim destacará o design gráfico. No entanto, se considerar que a melhor estratégia é se dedicar aos produtos, priorizará assim a interface do design de embalagens e do produto, por exemplo. As lojas e espaços de trabalho, também podem se apresentar com prioridade, devendo investir no design de interiores e na ergonomia. Ressalta-se que é necessário estabelecer prioridades e uma coerência entre essas, para que gradativamente o design seja inserido em todos os níveis. 
Figura 2 - Alocação de recurso de design
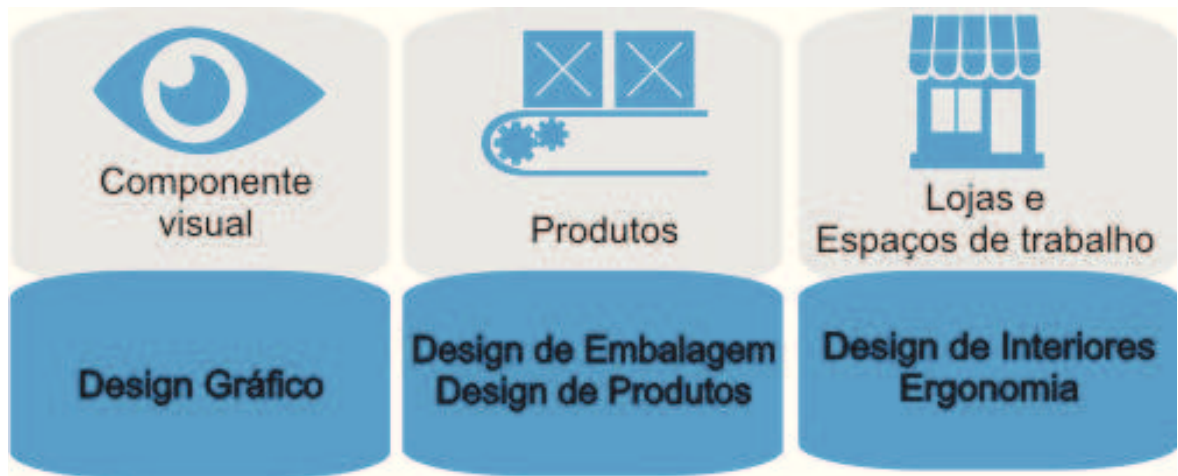

Fonte: Autora, adaptado de MOZOTA, 2011

Sendo necessário, para este trabalho, relacionar esses níveis de atuação com os obstáculos vivenciados por micro e pequenas empresas, cooperativas e associações em comunidades extrativistas, no próximo capítulo serão discutidas algumas barreiras para a valorização dos produtos extrativistas.

\section{DISCUSSÃO}

\subsection{PRINCIPAIS PROBLEMAS DACADEIA DEPRODUTOS EXTRATIVISTAS}

Para Diniz (2008), uma aplicação de forma generalizada de estratégias padronizadas é impraticável, em virtude da diversidade das configurações socioeconômicas e culturais. Além do mais, cada segmento deve estabelecer suas prioridades de acordo com os principais problemas enfrentados.

No entanto, nas atividades extrativistas é possível perceber similaridade entre os obstáculos das cadeias produtivas do babaçu, da castanha do Brasil, do açaí e dos recursos pesqueiros. É possível perceber, que existem diversos pontos em comum entre os problemas apresentados nas diferentes áreas extrativistas. No entanto, para se pensar em ações mais eficazes é necessário saber em que nível da gestão do Design esses problemas estão relacionados. Para isso, foram utilizados ícones para relacionar os problemas identificados com os níveis da gestão do Design.

No nível estratégico, os problemas apresentados por Diniz (2008) no estudo do extrativismo da Castanha do Brasil, pelo SEBRAE (2014) no diagnóstico da cadeia produtiva do babaçu, por Isaac-Nahum (2006) sobre os recursos pesqueiros, e por Jardim (2002) na pesquisa sobre a cadeia do açaí, são: 
Figura 3 - Problemas da cadeia extrativista no nível estratégico
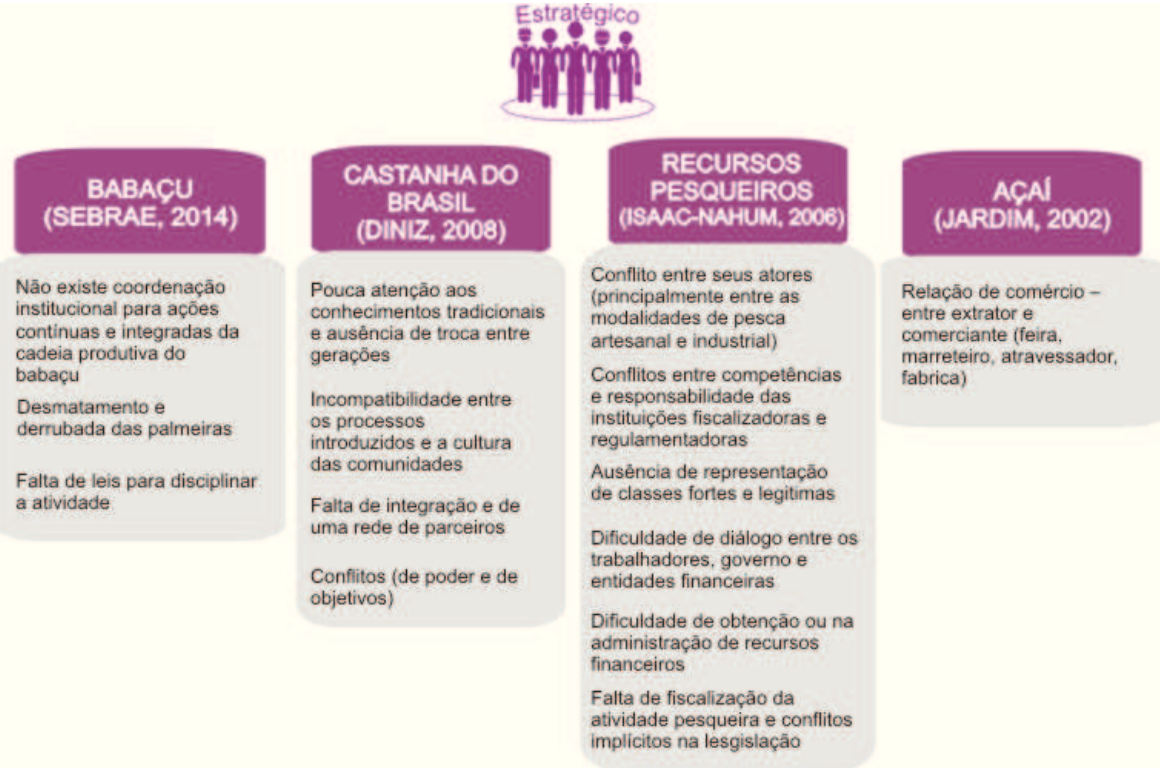

Fonte: Autora, adaptado de SEBRAE, 2004; Diniz, 2008; Jardim, 2002; Isaac-Nahum, 2006.

Neste nível as ações exigem um envolvimento da empresa como um todo, principalmente dos dirigentes gerais, pois estão relacionados à questões que não podem ser solucionadas internamente. Requer a buscar por relações externas com outras empresas e apoio governamental, no sentido de alterar leis e exigir fiscalização.

No nível funcional, os problemas das cadeias extrativistas estão nas relações internas, como pode ser observado na figura 4:

Figura 4 - Problemas da cadeia extrativista no nível funcional.

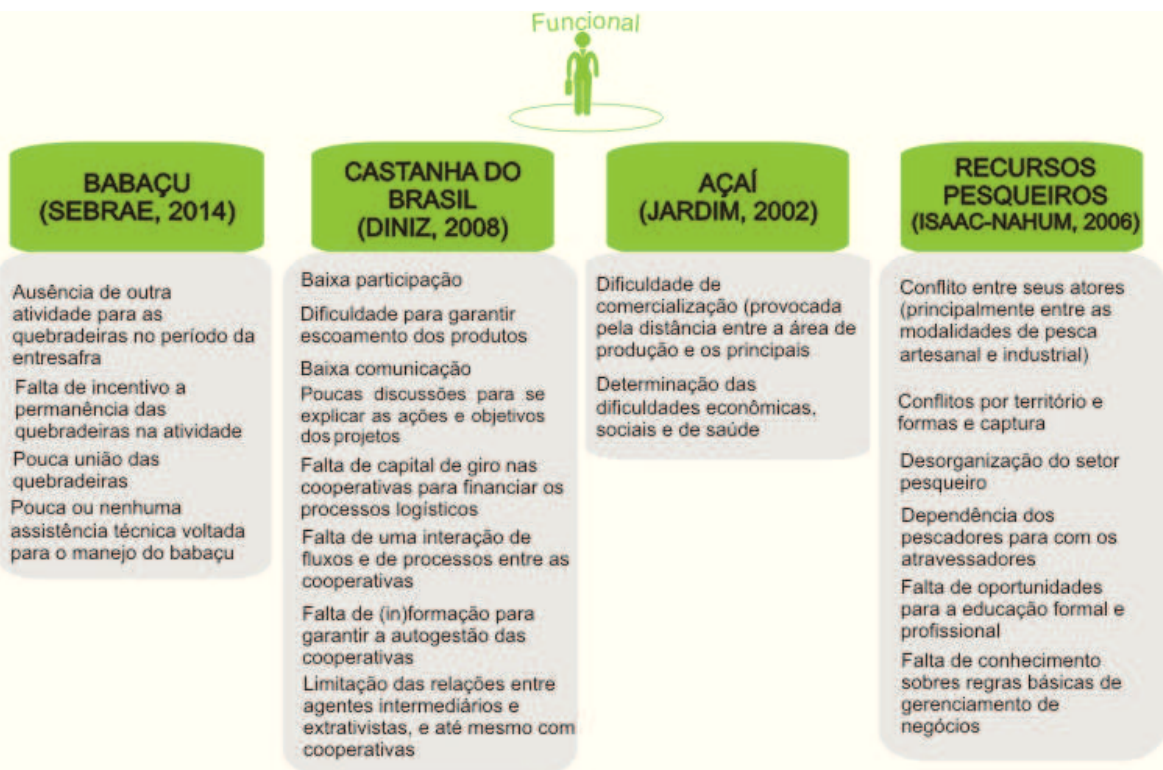

Fonte: Autora, adaptado de SEBRAE, 2004; Diniz, 2008; Jardim, 2002; Isaac-Nahum, 2006. 
Nesse nível as questões podem ser resolvidas internamente, porém o comprometimento com o design e a gestão devem ser priorizados, para que a comunicação entre os setores da empresa possa ser eficiente, e as ações definidas praticadas com eficiência.

No nível operacional os problemas são de ordem prática, ligados diretamente aos processos e projetos da cadeia produtiva, como podemos observar na figura 5:

Figura 5 - Problemas da cadeia extrativista no nível operacional.

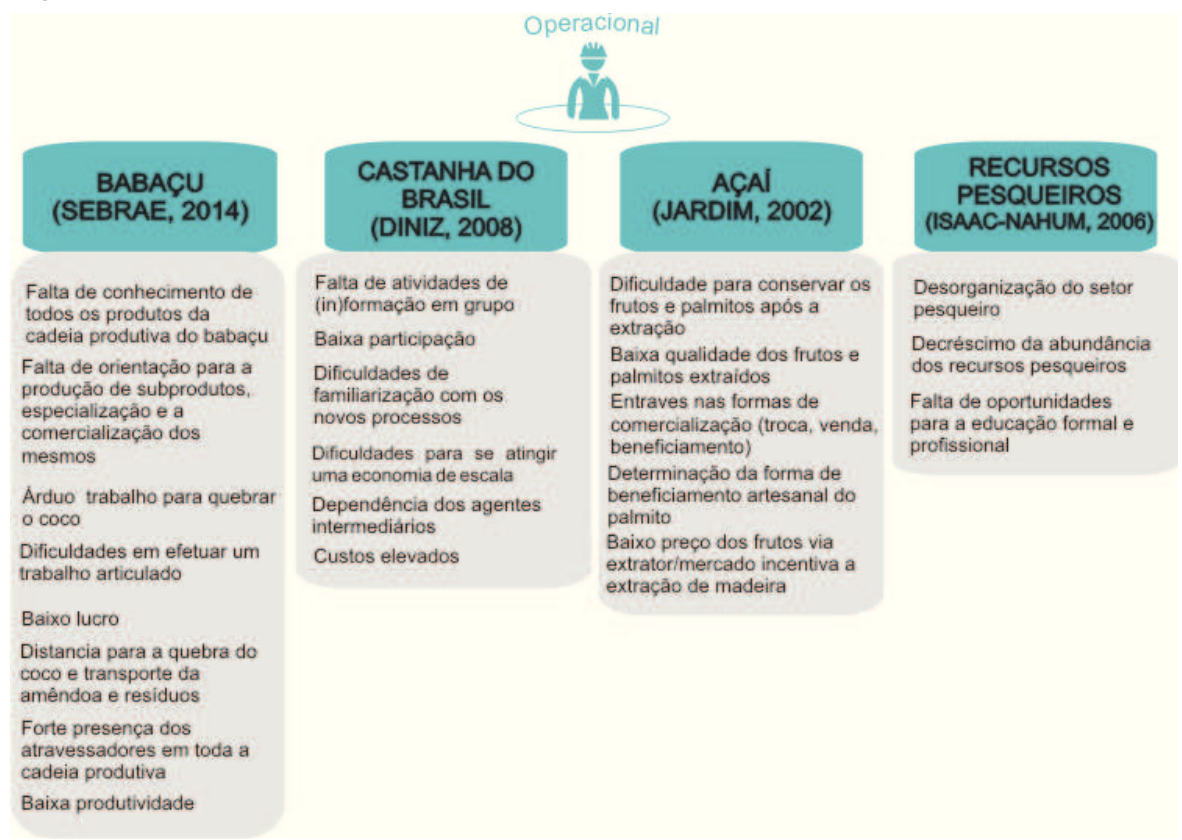

Fonte: Autora, adaptado de SEBRAE, 2004; Diniz, 2008; Jardim, 2002; Isaac-Nahum, 2006.

É importante ressaltar que nem todos os problemas identificados podem ser solucionados diretamente com recursos do Design, no entanto, é possível orientar ações de design na direção de uma solução, como por exemplo, na falta de leis para disciplinar uma atividade. Neste campo, o Design não pode apresentar soluções diretas para o problema, mas pode, a partir da estruturação do setor e da valorização dos produtos locais, promover uma mobilização entre os setores produtivos, comerciais e políticos com o objetivo de resolvê-lo, mesmo que as ações propostas ocorram somente no nível estratégico.

\section{CONSIDERAÇÕES FINAIS}

Neste trabalho foi possível perceber que o Design possui ferramentas úteis para a interpretação, identificação e classificação dos problemas identificados com a cadeia produtiva de produtos extrativistas. A gestão de Design pode auxiliar na resolução dos obstáculos de modo planejado, tornando compreensível os níveis onde ocorre o processo de tomada de decisões. Ao se analisar os problemas identificados nas cadeias produtivas do babaçu, da castanha do Brasil, do açaí, e dos recursos pesqueiros, resultou que dezesseis problemas se relacionam com o nível estratégico, dezenove com o nível funcional e vinte e cinco com o nível operacional. Este estudo é, sobretudo, útil para futuros trabalhos que tenham o objetivo de identificar e propor estratégias específicas de projeto para produtos, serviços e comunicação que apresentam interface com o setor extrativista e foco no desenvolvimento local sustentável. 


\section{NOTAS}

[1] Este artigo constitui parte da dissertação de mestrado defendida pela autora, em julho de 2015, que relaciona os níveis da gestão do Design com as estratégias de design sustentável que favorecem a valorização e a promoção dos recursos locais a partir do estudo da cadeia produtiva do babaçu no Município de Itapecuru Mirim (MA).

\section{REFERÊNCIAS}

BORJA DE MOZOTA, Brigitte; KLÖPSCH, Cássia; COSTA, Filipe Campelo Xavier da. Gestão do design: usando o design para construir valor de marca e inovação corporativa. Porto Alegre: Bookman, 2011.

\section{CASAS, D. D.; MERINO, E. A.D. Gestão de Design \& Design thinking: uma} relação possível. 2011. Disponivel em: http://incubadora.periodicos.ufsc.br/ index.php/eRevistaLOGO/ article/view/ 2844 /3378> Acesso em: 22/04/2015.

CORRÊA, M. S. A política da pilhagem. O Liberal, Belém, p. 2, 14 jul. 2005.

DINIZ, Janaína Deane de Abreu Sá. Avaliação-construção de produtos de desenvolvimento local a partir da valorização dos produtos florestais da Amazônia brasileira: caso da castanha-do-Brasil. Tese (doutorado) Universidade Federal de Brasília: Brasília, 2008.

HOMMA, Alfredo Kingo Oyama. Extrativismo, biodiversidade e biopirataria na Amazônia.Brasília, DF : Embrapa Informação Tecnológica, 2008.

ISAAC-NAHUM, V.J. Exploração e manejo dos recursos pesqueiros do litoral Amazônico: um desafio para o futuro. São Paulo: Cienc. Cult., 2006.

JARDIM, Mário Augusto Gonçalves. A cadeia produtiva do açaizeiro para frutos e palmito: implicações ecológicas e sócio-econômicas no Estado do Pará. Boletim do Museu Paraense Emílio Goeldi, Série Antropologia, Belém, v. 18, n. 2, p. 287-305, 2002.

KRUCKEN, L. Design e Território: valorização de identidades e produtos locais. São Paulo: Studio Nobel, 2009.

MURRIETA, Julio Ruiz; RUEDA, Rafael Pinzón (Ed.). Reservas extrativistas Cambridge: IUCN, 1995.

SEBRAE. Diagnóstico situacional participativo de arranjos produtivos- babaçu. 2003. Disponível em: < http://201.2.114.147/bds/bds.nsf/ F6060DA19AA6BC9183256F5B006D87C1/ \$File/ATT5MHQV.pdf>. Acessado em: 10/04/2015.

VOSGERAU, D.S.A.R.; ROMANOWSKI, J. P. Estudos de revisão: implicações conceituais e metodológicas. Revista Diálogo Educacional, 2014.

\section{VALKIRIA AIRES VIEGAS}

Possui graduação em Desenho Industrial (Design), com habilitação em produto. Mestre em Design, atuando na linha de sustentabilidade, materiais e processos. Atualmente é Técnica em Laboratório/Reciclagem do Instituto Federal de Educação, Ciência e Tecnologia do Maranhão, no qual atua no desenvolvimento de produtos como materiais recicláveis, enfatizando a sustentabilidade. Principais publicações: 
PORTO, M. S. PROPRIEDADES DAS MADEIRAS E SUAS RELAÇÕES COM OS REQUISITOS DE PROJETOS: INDICAÇÕES DE USO EM BRINQUEDOS DE MADEIRA. In: 11 Congresso Brasileiro de Pesquisa e Desenvolvimento em Design, 2014, Gramado. Anais do $11^{\circ}$ Congresso Brasileiro de Pesquisa e Desenvolvimento em Design. São Paulo: Editora Edgard Blücher, 2014. p. 2151.

ROCHA, L. T. C. ; PEREIRA, S. DE J. ; GUIMARÃES, K. DE L. M. ; VALPORTO, M. S. ; VIEGAS, V. A. MADEIRAS TROPICAIS QUANTO À DENSIDADE E COR PARA USO EM PAVIMENTAÇÃO. In: $11^{\circ}$ Congresso Brasileiro de Pesquisa e Desenvolvimento em Design, 2014, Gramado. Anais do $11^{\circ}$ Congresso Brasileiro de Pesquisa e Desenvolvimento em Design. São Paulo: Editora Edgard Blücher, 2014. p. 2171.

\section{ANDRÉ DE SOUZA LUCCA}

Bacharel em Desenho Industrial e Doutor em Ciências do Design. Entre 2012 e 2013 realizou Pós-doutorado na UFPR colaborando com a equipe do Núcleo de Design e Sustentabilidade. Atualmente é professor adjunto da UFMA e docente do Mestrado em Design.

Principais publicações:

LUCCA, A. S. Considerações metodológicas para a estruturação de uma abordagem coerente com o Design Sustentável. Revista Gestão Industrial, Ponta Grossa-PR, v.11, n.3, p. 91-104, set. 2015.

LUCCA, A. S. Design participativo para a valorização da produção do território. In: 10 P\&D Design Congresso Brasileiro de Pesquisa e Desenvolvimento em Design, 2012, São Luís. Anais do X Congresso Brasileiro de Pesquisa e Desenvolvimento em Design. São Luís: EDUFMA, 2012. v. 1. p. 2673-2682.

LUCCA, A. S. Competitividade territorial e inovação sustentável. In: III Simpósio Internacional de Design Sustentável, 2011, Recife. International Symposium on Sustainable Design 2011 Anais. Recife: Editora Universitária UFPE, 2011. v. 1. p. 431-445.

LUCCA, A. Recommendations for a socioethical and sustainable approach to the industrial design. In: 2nd Conference on Economic Degrowth for Ecological Sustainability and Social Equity, 2010, Barcelona. Proceedings Conference. Degrowth: Theory and ideas II. Barcelona: Research \& Degrowth/Universitat Autònoma de Barcelona, 2010. v. 1. 